This is an author produced version of a paper published in Journal of Scandinavian studies in criminology and crime prevention. This paper has been peer-reviewed but does not include the final publisher proof-corrections or journal pagination.

Citation for the published paper:

Gerell, Manne. (2017). Collective efficacy and arson : The case of Malmö.

Journal of Scandinavian studies in criminology and crime prevention, vol. 18, issue 1 , p. null

URL: https://doi.org/10.1080/14043858.2017.1298172

Publisher: Routledge

This document has been downloaded from MUEP (https://muep.mah.se) / DIVA (https://mau.diva-portal.org). 
Collective Efficacy and Arson in the City of Malmö, Sweden

Manne Gerell

Department of Criminology, Malmö University, Malmö, Sweden

Manne Gerell

Malmö Högskola

20506 Malmö

Sweden

$\underline{\text { manne.gerell@mah.se }}$

$+46406658125$ 


\section{Collective Efficacy and Arson}

The burning of cars and containers during social unrest has become a topic of both scholarly and public interest in Sweden over the past decade. Studies have suggested that social disorganization theory, or its modern expression collective efficacy, may be important for explaining why some neighborhoods experience elevated levels of arson and unrest while others do not. To date no study has explicitly studied the link between arson and collective efficacy at the neighborhood level. The present study attempts to fill this gap by analyzing the association between arson and collective efficacy in the city of Malmö, Sweden. Collective efficacy data from 96 neighborhoods were collected in 2012 in the Malmö Community Survey $(\mathrm{N}=4051)$. Arson data were collected from the rescue services, which employ GPS-receivers to accurately record the location of incidents. Multivariate regression models were fitted for the number of incidents of arson per capita, controlling for concentrated disadvantage, ethnic heterogeneity and residential stability. Results show no significant link between collective efficacy and arson following appropriate controls. This suggests that arson may depend on mechanisms other than collective efficacy, at least at the neighborhood level. Future research may need to focus on alternative theoretical explanations such as strain, or on other levels of analysis than neighborhoods.

Keywords: Arson, Collective Efficacy, Social Disorganization, Riots, Fire-setting

\section{Introduction}

Collective efficacy, defined as the combination of social cohesion and expectations for common action within a neighborhood, has been linked to a number of outcomes, notably violent crime, disorder and fear of crime (Gibson, Zhao, Lovrich, \& Gaffney, 2002; Sampson, Raudenbush, \& Earls, 1997; Sampson \& Wikström, 2008; Swatt, 
Varano, Uchida, \& Solomon, 2013). Collective efficacy is typically found to mediate a large portion of the association between crime and neighborhood levels of disadvantage, heterogeneity and residential instability (Sampson, 2012; Sampson et al., 1997). In the contemporary Swedish academic discourse, collective efficacy has also been discussed as a potential mechanism for explaining the relatively high prevalence of arson and riots in disadvantaged neighborhoods (Guldåker \& Hallin, 2013; Hallin, Jashari, Listerborn, \& Popoola, 2010; Malmberg et al., 2013). The above mentioned studies note that there appears to be an association between arson and disadvantage, segregation and similar structural neighborhood-level characteristics. To date only one small case study, focused on four neighborhoods divided into 12 micro-neighborhoods, has tested the association between collective efficacy and arson, noting a non-significant association (Gerell, 2013). However, the very small number of micro-neighborhoods meant there was insufficient statistical power to draw any firm conclusions from the study.

The present study attempts to further our knowledge on the association between collective efficacy and arson using formal modeling techniques, based on data from the city of Malmö. As such the present study will be the first to examine the issue properly on a city-wide scale. This is of interest for our understanding of the neighborhood-level mechanisms associated with arson, both in Sweden and elsewhere. It is also of interest in relation to the theory of collective efficacy, since this represents a new area of investigation with regard to the scope of collective efficacy. Arson can also be considered a form of disorder, which is commonly studied within the framework of the broken windows theory. This theory states that cues of social and physical disorder, if left unattended to, can lead to more disorder, and to more serious forms of crime. The present study thus contributes to the ongoing discussion of both broken windows theory and collective efficacy (Sampson \& Raudenbush, 1999; Wilson \& Kelling, 1982), in 
addition to adding to our empirical knowledge about arson in the city of Malmö, Sweden.

\section{Collective Efficacy Theory}

Although collective efficacy is a fairly new concept, its roots can be traced back to the early Chicago school of urban sociology (Kornhauser, 1978; Park \& Burgess, 1967; Shaw \& McKay, 1969). The theoretical notion of social disorganization theory was based on the finding that neighborhoods characterized by low socio-economic status (SES), low residential stability and high ethnic heterogeneity tended also to suffer from crime and other problems. One possible mechanism that could explain such associations was that neighborhoods with low SES, high ethnic heterogeneity and high residential instability would be expected to have difficulties maintaining a socially organized community, with social disorganization in turn helping to explain the occurrence of crime (Kornhauser, 1978).

Social disorganization theory was further developed by Sampson et al. (1997) in a seminal paper that established the concept collective efficacy. Collective efficacy builds on the existing theory by noting that the mere presence of social networks or organizations is not sufficient to reduce crime. Rather it is the content of networks, and the actions this content promotes, that is key to maintaining order and reducing crime (Sampson, 2012; Sampson \& Graif, 2009). Organizations and social networks may help promote social cohesion and trust (Sampson \& Graif, 2009), and cohesion is in turn the basis upon which informal social control can be generated to achieve common goals in a neighborhood, such as security and order (Sampson et al., 1997). Collective efficacy thus encompasses two dimensions of social capital, i.e. mutual trust and expectations to intervene for the common good (e.g. to maintain public order). The combination of the two is hypothesized to be important for our understanding of crime. The specific causal 
mechanism associated with collective efficacy may be understood from the work of Wikström \& Sampson (2003), who suggested that community rules were a key component to understanding residents' behavior. Community rules include norms, the cohesion around these norms, and the actions taken to uphold them, but can broadly be understood in the form of collective efficacy. The degree of collective efficacy in a neighborhood helps determine how much monitoring and enforcement of common rules is effected in public or semi-public spaces, for instance in the form of upholding order, expressing disapproval about deviant behavior, or monitoring the behavior of children and youth (Wikström \& Sampson, 2003).

Another key aspect of communities suggested by Wikström \& Sampson (2003) was the level of community resources, as reflected in e.g. social and economic disadvantage. Sampson et al. (1997) noted that structural variables in the form of concentrated disadvantage, immigrant concentration (heterogeneity of ethnic groups) and residential stability explained $70 \%$ of the variation between neighborhood levels of collective efficacy. Concentrated disadvantage was measured using an index constructed from variables related to SES; financial support and unemployment, combined with other measures of disadvantage, female-headed families, density of children and proportion of black residents (Sampson et al. 1997). In line with theoretical expectations, concentrated disadvantage, immigrant concentration and residential instability were found to be associated with violence. However, a large proportion of these associations, particularly in relation to concentrated disadvantage, was mediated by collective efficacy, which in itself presented a strong negative association with violence, even after the underlying disadvantage, heterogeneity and instability had been taken into account (Sampson et al., 1997). 
The finding that collective efficacy is negatively associated with crime, and particularly violent crime, has since been confirmed in studies from several parts of the world, including Stockholm, Sweden (Sampson \& Wikström, 2008), Malmö, Sweden (Gerell \& Kronkvist 2016), Peterborough, UK (Wikström, Oberwittler, Treiber, \& Hardie, 2012) and Brisbane, Australia (Mazerolle, Wickes, \& McBroom, 2010). Neighborhoods with low collective efficacy tend to have high crime, net of disadvantage, ethnic heterogeneity and residential instability. In the case of Chicago, for instance, it was noted that a two standard deviation increase in collective efficacy was associated with a 40\% reduction in homicide (Sampson et al. 1997). Recently, two European studies have noted very weak associations between collective efficacy and crime, highlighting the importance of further examining the issue in order to better elucidate the circumstances under which collective efficacy is associated with crime. In The Hague, Bruinsma, Pauwels, Weerman, and Bernasco (2013) found no association between collective efficacy and crime. In London, Sutherland, BruntonSmith, and Jackson (2013) found a weak association between collective efficacy and police reported violent crime, but no association with ambulance call outs for knife injuries. For London it was also noted that ethnic heterogeneity was positively associated with collective efficacy, and some part of the discrepancy in findings may be attributed to the differing contexts of cities and countries. Another potential explanation is that the definitions of neighborhoods employed have differed dramatically between studies of collective efficacy, ranging from below 100 residents per neighborhood to several thousand (Gerell, 2015). More broadly it has been shown that smaller types of neighborhoods are better at explaining collective efficacy, with arguments such as "smaller is better" being proposed with regard to the type of neighborhood definitions employed (Gerell, 2015; Wikström \& Oberwittler, 2009). Although the overall evidence 
points towards fairly strong associations between collective efficacy and crime, the evidence is more inconclusive in the European context.

\section{Collective Efficacy, Disorder and Arson}

Although the bulk of collective efficacy studies have focused on violent crime, the relationship between collective efficacy and disorder, as discussed within the framework of broken windows theory (Wilson \& Kelling, 1982), has also received some attention (Sampson \& Raudenbush, 1999; St Jean, 2009; Xu, Fiedler, \& Flaming, 2005). Broken windows theory states that disorderly behavior, social disorder, or the visible cues that such behavior results in, i.e. physical disorder, lead to more crime by signaling that no one cares, thus inviting criminal activity and discouraging residents from engaging in crime prevention (Wilson \& Kelling, 1982). While there is some disagreement as to whether disorder has an independent effect on crime, or whether both crime and disorder are best seen as being related to collective efficacy, studies tend to find significant negative associations between collective efficacy and disorder either way (Sampson \& Raudenbush, 1999; Xu et al., 2005). One Swedish study found no association between social disorganization and violent victimization, but instead suggested that social disorganization may be of importance for disorder (Estrada \& Nilsson, 2007). Social disorganization is the theoretical predecessor of collective efficacy. Theoretically the construct is very similar, but in the Estrada and Nilsson (2007) study it was measured by means of its correlates, such as concentrated disadvantage and other similar factors discussed above.

Studies on disorder typically include vandalism as a key component of disorder. While arson may be seen as a form of vandalism, however, it is rarely explicitly included in operationalizations of disorder. Arson is explicitly mentioned as a key type of disorder by Wilson and Kelling (1982), and some studies have discussed it as such 
(Drucker, 2011; Gerell, 2016). More generally, a key component of physical disorder is the visual cue it sends, and arguably a burnt out car wreck transmits a very strong visual cue. In my earlier study of four neighborhoods in the city of Malmö, it was also shown that arson and (other forms of) physical disorder have a similar geographical distribution and clustering (Gerell, 2013). I also noted a non-significant association between arson and collective efficacy, but a significant association between collective efficacy and other forms of observed disorder. The study was very small, however, being focused on just 12 micro-neighborhoods, and the results are therefore very uncertain.

The association between collective efficacy and arson has received scholarly attention, not least in relation to riots in Sweden (Guldåker \& Hallin, 2013; Hallin et al., 2010; Malmberg et al., 2013). In a nation-wide Swedish study, Malmberg et al. (2013) noted that car arson was associated with residential segregation, the proportion of youth and the proportion of welfare recipients, and the authors went on to argue that such associations may indicate the significance of mechanisms of collective efficacy for explaining riots, since collective efficacy quite commonly mediates the association between disadvantage and crime. Guldåker and Hallin (2013) found a strong association between arson and their index of living conditions, a broad concept intended to capture neighborhood-level variables previously identified as important in relation to arson. Living conditions for the city of Malmö were measured as an index of the proportion of youth, the number of residents per room, the proportion with no higher education, the proportion of unemployed and the proportion of foreign-born residents, and the study discussed collective efficacy as a potential preventive measure. Finally, Hallin et al. (2010) noted that a lack of collective efficacy may be one contributory factor in relation to the emergence of large scale riots in the city of Malmö in 2008 and 2009 . $^{\mathrm{i}}$ 
On the topic of riots, a study has also been conducted into the riots in Gothenburg in the autumn of 2009, which highlights micro-sociological explanations for the spread of rioting (Björk, 2013). Björk (2013) argues that while low SES and similar may help explain where rioting breaks out, it cannot explain when. This is an important distinction to keep in mind, and future research will need to focus both on the mechanisms that can explain where riots take place, and the mechanisms that can explain when riots break out. The present study will be the first to formally test the association between collective efficacy and arson, which may be viewed as representing a partial answer to the first question. In doing so, the study may also provide a tentative answer to the question of whether social unrest in disadvantaged neighborhoods can be understood through the lens of collective efficacy theory. Traditionally, collective efficacy is considered to be a fairly stable phenomenon, and might thus not be considered relevant in relation to the question of when riots break out, but several potential pathways for an association could be considered. It is possible for instance that community rules (Wikström \& Sampson, 2003) and collective efficacy may at times become temporarily weakened, and that those are the times when riots take place. Another possibility is that low collective efficacy is a necessary but not sufficient condition for riots, and that it needs to be complemented with micro-sociological factors (Björk 2013) in order to understand when riots break out.

\section{Arson and the City of Malmö}

The city of Malmö is the third largest city in Sweden with over 300,000 residents (Malmö stad, 2014). It is situated in the southernmost part of Sweden, in the region of Skåne. Malmö has a higher unemployment rate and a higher proportion of foreign-born residents than Sweden as a whole (Malmö stad, 2014; Statistics Sweden, 2013). It has been described as a city with high crime compared to other Swedish cities (Ekström, 
Eriksson, Korsell, \& Vesterhav, 2012), but the level of crimes reported to the police has declined steadily since 2009 (Malmö stad, 2016). The city was troubled by large-scale rioting in the Rosengård district in the years 2008 and 2009 (Hallin et al., 2010). Levels of arson are high compared with other Swedish cities, and increased rapidly in the early 2000s, but started decreasing in 2010 (Guldåker \& Hallin, 2013). Incidents of vehiclerelated arson, which is commonly associated with riots, show a similarly increasing trend during the first half of the 2000s, and a spike towards the end of the same decade (Figure 1).

Figure 1. Intentional vehicle-related arson per capita in the city of Malmö. Source MSB/IDA.

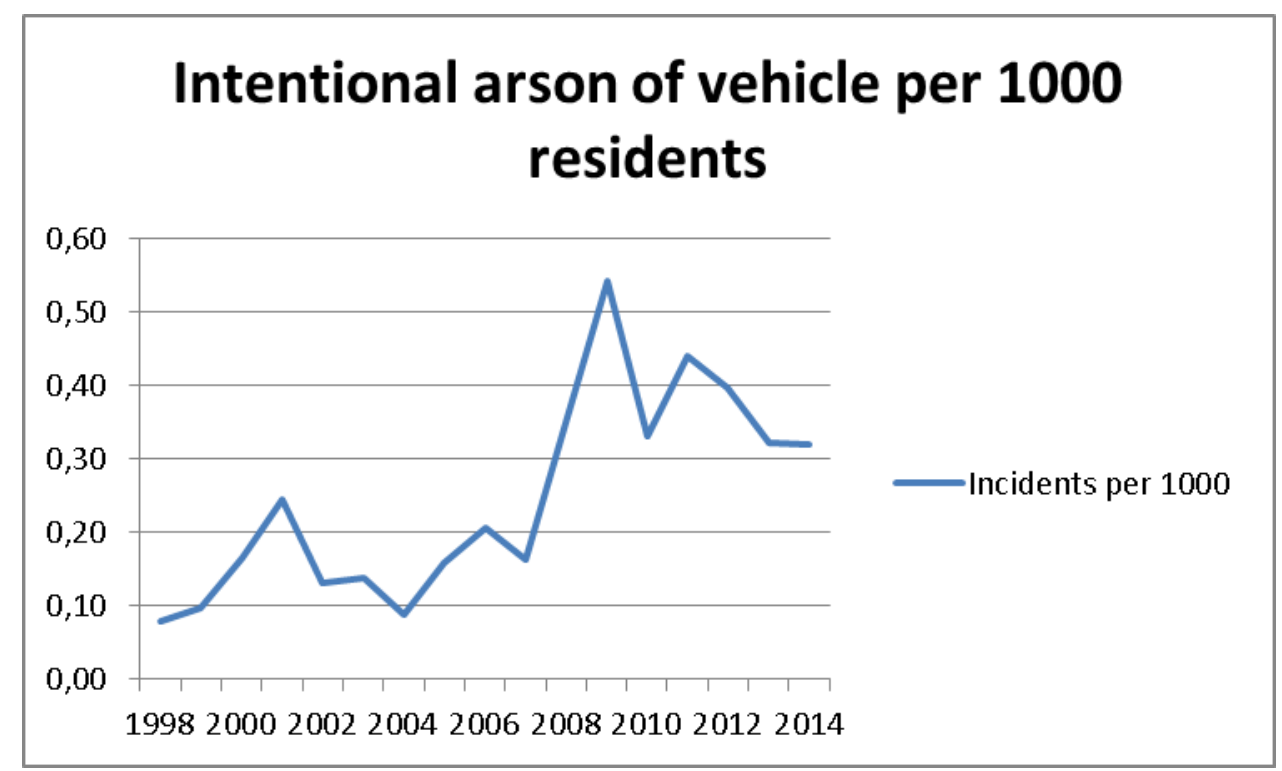

The city of Malmö is divided into 136 city districts, most of which include residential areas, but some of which consist of parks, industrial areas or other nonpopulated areas. The city districts were constructed by the municipality based on both content, e.g. type of buildings or facilities, and boundaries such as major roads. Figure 2 shows the city districts, with neighborhoods excluded from the study due to low 
population or few community survey respondents marked (see below) and the remaining 96 neighborhoods labeled according to the 2013 rate of vehicle-related arson. [Figure 2 near here]

\section{Research Design}

The present study employs established methods for modeling the association between collective efficacy and neighborhood level crime after controlling for concentrated disadvantage, (ethnic) heterogeneity and residential stability (Sampson et al., 1997; Bruinsma et al., 2013). To ensure the robustness of the models, different versions of both dependent and independent variables were tested. In addition, a variable for the proportion of youth was tested separately in an alternative model specification due to the importance this variable has been found to have in previous studies of neighborhood-level arson in Sweden (Guldåker \& Hallin, 2013; Malmberg et al., 2013). The variables have been temporally ordered so that register data from 2011 on disadvantage and similar factors can be associated with survey data from 2012 and the arson outcome variable in 2013. The models were fitted using multivariate linear regression in SPSS and negative binomial regression in Stata.

\section{Data}

\section{Independent variables}

Collective efficacy was measured in a community survey from 2012 of 4,195 respondents distributed over 104 neighborhoods; only 96 of these neighborhoods were used in the present study however $(n=4,051)$. The excluded neighborhoods had fewer than 200 residents and/or fewer than 20 respondents in the survey (see Figure 2). The collective efficacy measure is based on five items each for cohesion and informal social control. The cohesion items measure the extent to which the respondents agree that: $i$ ) "people in my neighborhood generally get along well”, $i i)$ "people in my neighborhood 
are helpful", iii) "people in my neighborhood can be trusted", iv) "my neighborhood is characterized by a strong cohesion among neighbors", and v) "people in my neighborhood share common values" (strongly disagree, disagree, neither agree nor disagree, agree, strongly agree) (Ivert, Chrysoulakis, Kronkvist, \& TorstenssonLevander, 2013). The informal social control items measure the extent to which the respondents would be likely to do something about $i$ ) "a group of children who were skipping school and hanging out in the neighborhood", ii) "a group of children spraypainting graffiti on neighborhood walls", iii) "a child acting disrespectfully towards an adult", $i v$ ) "a fight that broke out in front of their house", and v) "an ongoing car burglary in front of the house" (very likely, likely, neither likely nor unlikely, unlikely, very unlikely) (Ivert, Chrysoulakis, Kronkvist, \& Torstensson-Levander, 2013).

Respondents with scores for less than two items each for cohesion and informal social control were excluded, and for the remaining respondents, missing values were set to the mean of the respondents' other responses. Indexed values were then calculated for both cohesion and informal social control. The cohesion and informal social control indexes were then combined into a collective efficacy index with high reliability (alpha=.89). Fitting multi-level models (e.g. Bryk \& Raudenbush 1992) with collective efficacy as the outcome yields very high Intra Class Correlations (ICC) and values for ecological reliability (lambda), reflecting both a fairly high number of respondents per neighborhood $(\mathrm{n}=42.2)$ and a high level of inter-rater reliability. Unconditional models result in an ICC of $17.7 \%$ and a lambda of 0.9 , with these values declining to $13.4 \%$ (ICC) and 0.87 (lambda) following the introduction of individual level controls. The individual level controls employed were: Sex, age, having a university education, being single, a homeowner, born outside Sweden, employed part-time, a student, retired, unemployed, and having lived for at least one year in one's current home. 
Measures of concentrated disadvantage, residential instability and ethnic heterogeneity were constructed based on a factor analysis of variables used in previous studies on collective efficacy, as shown in Table 1 (Sampson et al., 1997; Sampson \& Wikström, 2008; Bruinsma et al., 2013). A number of variables were considered on the basis of previous studies of collective efficacy (Sampson et al., 1997; Sampson \& Wikström, 2008; Bruinsma et al., 2013) and of arson in Sweden (Malmberg et al., 2013; Guldåker \& Hallin, 2013). The data from Malmö municipality employed in the indexes include the proportion of unemployed, the proportion on public assistance, the number of persons per room, median income and the proportion of residents who moved away from the neighborhood. In addition, data from the community survey on the mean number of years residents had lived in the neighborhood were also used. To capture ethnic heterogeneity, a Herfindahl index (Gibbs \& Martin, 1962) was calculated yielding the odds of two randomly drawn individuals in the neighborhood having the same country/region of origin (birth). The ethnic heterogeneity index is strongly associated with variable measuring the proportion of foreign born residents, but, at least theoretically, taps into a different construct. This can be shown by comparing a hypothetical neighborhood in which everyone is born in Denmark to a hypothetical neighborhood in which everyone is born in Sweden. This would yield opposite values for the proportion of foreign born individuals ( 0 vs 100), but identical values for ethnic heterogeneity (no heterogeneity in either case).

Some discrepancies with theoretical expectations relative to Sampson et al. (1997) were noted, which motivated certain changes to the indexes. The proportion of youth did not load on the concentrated disadvantage index, and was therefore dropped from it. The same measure did present a strong negative loading on residential instability, but was not included in this index since it would be hard to motivate theoretically. ${ }^{\text {ii }}$ The 
proportion of youth was nonetheless tested as a separate variable in the final models, due to its importance in prior studies on arson in Sweden (Guldåker \& Hallin 2013; Malmberg et al. 2013). The factor analysis also firmly placed the ethnic heterogeneity variable within the concentrated disadvantage index, with a factor loading of .926, and the paper's main analysis employs a combined disadvantage and heterogeneity index. However, all models have also been fitted with the two variables separately, since they theoretically tap into distinctly different constructs. ${ }^{\text {ii }}$

[Table 1 about here]

The resulting concentrated disadvantage and ethnic heterogeneity index is thus based on the proportion of households on public assistance, proportion unemployed, median income (reverse coded), proportion of foreign-born residents, number of residents per room and ethnic heterogeneity (all based on municipal register data from 2011, see Table 2 for descriptives). Residential instability is measured using an index of the proportion of residents who moved away from the neighborhood in 2011, and the mean number of years people have lived in the neighborhood according to the community survey. All variables were standardized, and weighted by their factor score.

\section{Dependent variable}

Arson data are drawn from the Rescue Service in southern Sweden (Räddningstjänsten Syd), and are based on incidents where the rescue services have responded to a fire that a fire inspector deems to have been intentionally started with malicious intent ("brand anlagd med uppsåt"). ${ }^{\text {iv }}$ Only arsons coded as "not in building” have been used, since these are hypothesized to better capture riot-like incidents and similar. The rescue services employ GPS-devices to accurately capture the location of such incidents, which 
provides a high level of geographic precision by comparison with police data, which commonly employ an address that needs to be accurately placed, and which is sometimes incomplete. Data on outdoor arson for the year 2013 were plotted using the geographical information system software ARCGIS 10, and were aggregated to the neighborhood level; the data were plotted separately for vehicle-related arson, with a definition based on the object of arson having been coded as a motorcycle, trailer, car or similar (See Table 2 for descriptives). Due to the highly skewed distribution of the outcome variable, the natural logarithm was used in the main analysis, and all models were also fitted using negative binomial regression using the population as the exposure variable. ${ }^{\mathrm{v}}$ In addition, models have also been fitted for the same types of arson for the period January $1^{\text {st }} 2012$ to October $31^{\text {st }} 2014$ in order to reduce the risk of potential bias from single years. In total then, three versions of the dependent variable are tested, outdoor arson 2013, vehicle-related arson 2013 and outdoor arson 2012-2014. [Table 2 about here]

\section{Results}

The bivariate correlations for the variables included in the analysis are presented in Table 3. All correlations are in the directions that would be expected based on theory, although it is notable that residential instability is weakly and non-significantly associated with arson. Collective efficacy is associated with all three arson measures, but shows a much stronger association with the 2012-2014 data than the 2013 data. Concentrated disadvantage and ethnic heterogeneity both register fairly strong associations with arson, and very strong associations with collective efficacy. As discussed in the research design section, disadvantage and heterogeneity are also strongly correlated $(\mathrm{r}=.89)$. Due to the methodological concerns relating to the factor 
analysis discussed previously, and to the risk of biased estimates due to multicollinearity issues, the main analysis in this paper uses the combined estimate of ethnic heterogeneity and concentrated disadvantage, which is almost perfectly correlated with concentrated disadvantage $(\mathrm{r}=.997)$. As mentioned previously, the proportion of youth was dropped from the disadvantage index due to low factor loadings, but is included in an alternative model specification as a separate variable. Bivariate correlations show that it is significantly, but weakly, associated with arson and disadvantage, and negatively associated with residential instability.

[Table 3 near here]

Table 4 shows the main results of the study. In Model 1, the combined disadvantage and heterogeneity index shows a significant positive association with arson, while residential instability presents a negative, and insignificant, association. In Model 2 collective efficacy is added, but this does not mediate the association between disadvantage and arson, nor is collective efficacy significantly associated with arson. Indeed, adding collective efficacy to the model barely affects the explained variance at all. The results remain substantively the same when using the longer time period for the outcome variable (2012-01-01 to 2014-10-31), although it may be noted that the explained variance then becomes much greater (.46), suggesting a better model fit (results not shown).

[Table 4 near here]

The same models were fitted on the outcome of vehicle-related arson only, since this was the outcome preferred by Malmberg et al. (2013) to operationalize social unrest. Results are substantially the same. There is no association between collective efficacy and arson relating to cars, motorcycles, trailers and similar at the neighborhood level in the city of Malmö (results not shown). 
The analysis was also modelled with the heterogeneity variable separately, since theoretically this represents an important variable in its own right. This has no impact on collective efficacy, but in some models renders concentrated disadvantage nonsignificant as well. It should be noted, however, that these models suffer from multicollinearity, with variance inflation factor scores in the range of 4-6 for collective efficacy, concentrated disadvantage and heterogeneity (results not shown).

Since the proportion of youth was dropped from the concentrated disadvantage index due to a poor fit in the factor analysis, the models were also fitted with the proportion of teenage residents as an additional independent variable. This presents no association with outdoor arson for 2013, nor for 2012-2014 (data not shown). It does however present a significant association with vehicle-related arson, as shown in Table 5. This association remains if concentrated disadvantage and ethnic heterogeneity are separated: coefficient for concentrated disadvantage $=0.393, p=.015$, coefficient for proportion of youth $=0.184, \mathrm{p}=.008$, all other variables non-significant). [Table 5 near here]

Collective efficacy does not mediate the association between the proportion of youth and vehicle-related arson, but the youth variable does mediate some of the association between disadvantage and vehicle-related arson (the disadvantage coefficient drops from .246 to .201$)$. ${ }^{\text {vi }}$ Since the outcome variables are highly skewed and overdispersed, all models have also been fitted using negative binomial regressions with population as the exposure variable. This has some impact on the substantive results, with concentrated disadvantage being rendered non-significant in relation to arson in 2013 ( $p=.103$, but not for arson in 2012-2014 nor for vehicle-related arson). It is also important to note that the association between the proportion of youth and vehicle-related arson disappears. The proportion of youth fails to reach significance 
when modeled using negative binomial regression, and the association between youth and vehicle-related arson will therefore be disregarded, while the other results appear to be more robust to model specifications. In particular, the finding that collective efficacy is not associated with arson holds across all models and all model specifications with appropriate controls.

\section{Discussion and Conclusion}

Collective efficacy has been theoretically (Malmberg et al., 2013; Guldåker \& Hallin, 2013) linked to arson, but there is no prior empirical evidence on the topic. In this study the aim was to test whether a link can be shown between collective efficacy and arson. The present study finds that there is no neighborhood-level association between collective efficacy and outdoor arson when appropriate controls are included. This result is highly stable across all model specifications in which concentrated disadvantage is included. This suggests that economic and social disadvantage, which have previously been suggested to be associated with arson through the mechanism of collective efficacy (Hallin et al., 2010; Malmberg et al., 2013), operate through some other mechanism to explain arson in the city of Malmö. While the association between disadvantage and arson was fairly stable, it too was rendered non-significant in some of the robustness tests. The results of this paper further show that the proportion of youth presents a fairly weak association with disadvantage, in contrast to previous studies on collective efficacy (Sampson et al., 1997) and this measure was therefore not included in the disadvantage index.

Since prior research (Guldåker \& Hallin 2013; Malmberg et al. 2013) has suggested that the proportion of youth may constitute an important variable when it comes to understanding arson, it was included as a separate variable in the analysis. While the proportion of youth was a significant predictor of vehicle-related arson in the 
linear models, the robustness tests using negative binomial regression resulted in the proportion of youth being rendered non-significant. Although an association between the proportion of youth and vehicle-related arson cannot be ruled out, the present paper suggests that this measure is not of major importance once social and economic disadvantage and/or ethnic heterogeneity have been taken into account. While this means that the findings from Malmberg et al. (2013) cannot be fully replicated, the results of the current study nonetheless point in a similar direction. More specifically, neighborhoods with a high rate of vehicle-related arson tend to have a high proportion of youth, a high degree of disadvantage, a high degree of ethnic heterogeneity, and a low degree of collective efficacy. In the multivariate models, however, only disadvantage was found to be significantly associated with arson and vehicle-related arson, and even this association disappears in some of the model specifications. The variables used in the present study are not the same as those employed by Malmberg et al. (2013), but broadly speaking, the association between disadvantaged/segregated neighborhoods and arson can tentatively be confirmed, while the proposed mechanism of collective efficacy is falsified, which highlights a need to look at other theories in order to explain neighborhood arson.

Perhaps, for example, arson is best explained by anomie or strain theories, which view structural strain, the pressures associated with an unequal society, as a key mechanism in explaining crime. Such theories show some promise in explaining neighborhood crime, although the empirical support for these theories has been described as relatively thin (Pratt \& Cullen, 2005). A recent macro-level study by Chamberlain and Hipp (2015) showed that strain theory (Agnew, 1999) was better at explaining property crime than social disorganization theory. Neighborhoods in which residents perceive an unequal distribution of resources thus exhibit higher levels of 
property crime (Chamberlain \& Hipp, 2015). Similarly, Warner and Fowler (2003) found that neighborhoods in which respondents had been threatened, cheated, or harassed by the police, which were together viewed as being indicative of strain, exhibited higher levels of violence following controls for both disadvantage and informal social control. The fact that Warner and Fowler (2003) thus have a very different operationalization of strain from that employed by Chamberlain and Hipp (2015), while both papers cite Agnew (1999) as a key source, points to a need for further research on the theoretical mechanisms associated with strain.

Although I know of no large quantitative studies on arson or rioting based on such a theoretical perspective, it would make sense to look in this direction now that social disorganization/collective efficacy appears not to be a key mechanism (at least in the city of Malmö, Sweden). This would seem a reasonable next step based on the analysis by Kornhauser (1978), which shows that both strain and social disorganization theory attempt to explain the association between social and economic disadvantage and crime, but from opposite viewpoints. With one of the perspectives ruled out, the remaining perspective should receive more attention. It may be particularly fruitful to consider such issues from the perspective of youth, since several studies have discussed how youth often tend to be involved in fire-setting (Lowenstein, 2003; Pooley \& Ferguson, 2015; Terjestam \& Ryden, 1999), which also has been shown to be the case at the area-level in both the present study and previous research (Guldåker \& Hallin, 2013; Malmberg et al., 2013). Large groups of youth who are experiencing strain due to unequal life chances would appear to constitute a likely explanation for arson, and future research would do well to test such a hypothesis through direct measurements of experienced strain and/or perceived inequality. 
Research on area-level mechanisms to explain arson could also be explored in conjunction with micro-sociological studies on how such practices spread. As has been discussed by Björk (2013), there may be contagion effects associated with arson, and from this perspective it may be fruitful to explore geographical interaction and contagion, in addition to non-linear effects, whereby low levels of arson predicted by area-level mechanisms may be multiplied by such micro-sociological mechanisms. This can also be considered in relation to the way in which arson is often a group phenomenon, and how youths organize themselves and assume different roles in the course of fire-setting activities (Uhnoo, 2016). In particular, the importance of the presence of others for fire-setting, to increase the fun or excitement involved (Uhnoo, 2016) could possibly also add to an area-level understanding, with areas characterized by a greater number of potential co-offenders presenting better possibilities for such interactions to take place. Such possibilities could possibly be linked to the proportion of youth, with more youth being likely to represent more options for co-offending, but in this paper the link between youth and arson was not found to be stable. Some models did however show an association between the proportion of youth and outdoor arson, and this might be considered a potential area for more detailed investigation in the light of prior area-level findings highlighting the importance of youth (Malmberg et al. 2013; Guldåker \& Hallin, 2013).

Another way of understanding why some neighborhoods exhibit more arson than others is to simply consider the composition of neighborhoods. Composition can be understood as the impact associated with the sum of the individuals living there with regard to demographics, socioeconomic status and other variables of interest. Research on the neighborhood's significance for individual criminality in Sweden has shown that there is no causal link between living in a deprived neighborhood and youths 
committing offences (Sariaslan, Långström, D’Onofrio, Hallqvist, Franck, \& Lichtenstein, 2013).

This question is of course somewhat different from that examined in the current study, which focuses on where arson takes place rather than where arsonists live, but research has shown that arson is typically committed fairly close to home (Kocsis \& Irwin, 1997; Meaney, 2004). If arson typically takes place close to the offender's home, it may be worthwhile considering the abundance of research on individual-level predictors based on a clinical or psychological perspective, which has linked arson to e.g. mental illness, low self-control and alcohol problems (see Lowenstein, 2003 for an overview). On the basis of this research, a plausible explanation for some neighborhoods exhibiting more arson than others might simply be that more individuals with a high propensity for arson tend to live there. From a preventive perspective, such an understanding would mean that we should focus on helping and supporting the individuals who live in deprived neighborhoods, rather than focusing on the neighborhoods themselves. It can be argued, however, that a combination of different measures is needed to achieve success in prevention. A recent paper on the prevention of school fire-setting suggested that individually focused interventions should be combined with situational prevention, and efforts to build trust between youth, schools and/or rescue service personnel (Uhnoo, Persson, Ekbrand, \& Lindgren, 2015).

While the present paper has shown that there is no neighborhood-level association between collective efficacy and arson, it should be noted that I, in previous research from the city of Malmö, have suggested that both arson (Gerell, 2016) and collective efficacy (Gerell, 2015) are better understood at smaller scales of geography such as micro-neighborhoods. It is possible therefore that an association exists on a smaller scale, but considering the relative stability of correlations across different 
geographical levels noted by Robert Sampson (2012), it would appear likely that other theories are better at explaining arson, and perhaps in particular vehicle-related arson and rioting.

It should also be noted that although there is no direct association between collective efficacy and arson in the city of Malmö, collective efficacy may be of importance in disadvantaged neighborhoods in other ways. Collective efficacy has been linked to fear of crime in the city of Malmö (Ivert et al., 2013), and if levels of fear could be reduced, this may well also improve the functioning of the local community and help facilitate the work of authorities such as the police in the neighborhood, with fewer people being afraid to report crimes, to act as witnesses, or to intervene in ongoing incidents. The variation in findings regarding collective efficacy highlights a need for better insight into how collective efficacy functions. Furthermore, little is known on how collective efficacy may be strengthened. In the future, there is a need for experimental studies that can help shed some light both on how and when collective efficacy functions, but also how it can be strengthened. If experiments were to be successful in increasing collective efficacy, the effects on different types of crime could also be examined, thus furthering our understanding of neighborhood-level mechanisms and crime.

\section{Limitations}

The present study suffers from several limitations which should be noted. As has been noted in the discussion, it is possible that the neighborhood definitions employed mask within-neighborhood differences that would help provide a more adequate understanding of the social mechanisms that explain arson. In particular it is possible that such social mechanisms function on a smaller geographical scale than that 
examined in this study, where the focus has been directed at neighborhoods comprising an average of about 3,000 residents.

In addition, it should be noted that generalizations should be made with caution, out of consideration for both the national context of Sweden, and the city context of Malmö. In particular, the city of Malmö stands out as having a higher level of arson, lower SES, and a larger number of immigrants than a typical Swedish city.

\section{Acknowledgements}

The author wishes to acknowledge the major contribution made by Karl Kronkvist of Malmö University in the collection, management and coding of the independent variable data.

\section{References}

Agnew, R. (1999). A general strain theory of community differences in crime rates. Journal of Research in Crime and Delinquency, 36, 123-155. doi:

$10.1177 / 0022427899036002001$

Björk, M. (2013). Contours of an Interaction Sequence in Rioting: The Gothenburg Disturbances of 2009. Journal of Scandinavian Studies in Criminology and Crime Prevention, 14, 24-42. doi: 10.1080/14043858.2013.773682

Bruinsma, G. J., Pauwels, L. J., Weerman, F. M., \& Bernasco, W. (2013). Social Disorganization, Social Capital, Collective Efficacy and the Spatial Distribution of Crime and Offenders An Empirical Test of Six Neighbourhood Models for a Dutch City. British Journal of Criminology, 53, 942-963. doi: 10.1093/bjc/azt030 Bryk, A. S., \& Raudenbush, S. W. (1992). Hierarchical linear models: Applications and data analysis methods. Newbury Park, NJ: Sage.

Chamberlain, A. W., \& Hipp, J. R. (2015). It's all relative: Concentrated disadvantage within and across neighborhoods and communities, and the consequences for 
neighborhood crime. Journal of Criminal Justice, 43, 431-443. doi:

10.1016/j.jcrimjus.2015.08.004

Drucker, J. (2011). Risk Factors of Arson. In J.M. Caplan \& L.W. Kennedy (Eds.), Risk terrain modeling compendium. Newark: Rutgers Center on Public Security.

Ekström, E. Eriksson, A. Korsell, L. \& Vesterhav, D. (2012). Brottslighet och trygghet $i$ Malmö, Stockholm och Göteborg. En kartläggning. [Crime and Fear of Crime in Malmö, Stockholm and Gothenburg. An investigation] Stockholm: Brottsförebyggande rådet.

Estrada, F. \& Nilsson, A. (2007). Risky Neighbourhood or Individuals at Risk? The Significance of Neighbourhood Conditions for Violent Victimization in Residential Areas. Journal of Scandinavian Studies in Criminology and Crime Prevention, 8, 2-21. doi: $10.1080 / 14043850701299727$

Gerell, M. (2013). Skadegörelse, bränder, grannskap och socialt kapital.[Vandalism, arson, neighborhoods and social capital] Malmö: Malmö University Publications in Urban Studies (MAPIUS)

Gerell, M. (2015). Collective Efficacy, Neighborhood and Geographical Units of Analysis: Findings from a Case Study of Swedish Residential Neighborhoods. European Journal on Criminal Policy and Research, 21, 385-406. doi: 10.1007/s10610014-9257-3

Gerell, M. (2016). Smallest is Better? The Spatial Distribution of Arson and the Modifiable Areal Unit Problem. Journal of Quantitative Criminology. Advance Online Publication. doi: 10.1007/s10940-016-9297-6

Gerell, M. \& Kronkvist, K. (2016). Violent Crime, Collective Efficacy and City-Centre Effects in Malmö. British Journal of Criminology, Online first, doi 10.1093/bjc/azw074 
Gibbs, J. P., \& Martin, W. T. (1962). Urbanization, technology, and the division of labor: International patterns. American sociological review, 27, 667-677. Retrieved from http://www.jstor.org/stable/2089624

Gibson, C.L., Zhao, J., Lovrich, N.P. \& Gaffney, M.J. (2002). Social integration, individual perceptions of collective efficacy, and fear of crime in three cities. Justice Quarterly, 19, 537-564. doi: 10.1080/07418820200095341

Guldåker, N., \& Hallin, P.-O. (2013). Stadens bränder. Del 1: Anlagda brander och Malmös sociala geografi. [Arson in the City. Part 1. Arson and the social geography of Malmö] Malmö: Malmö University Publications in Urban Studies.

Hallin, P.-O., Jashari, A., Listerborn, C. \& Popoola, M. (2010). Det är inte stenarna som gör ont. Röster från Herrgården, Rosengård - om konflikter och erkännande. It's not the stones that hurt. Voices from Herrgården, Rosengård-about conflicts and recognition] Malmö: Malmö University Publications in Urban Studies.

Ivert, A.-K., Chrysoulakis, A., Kronkvist, K., \& Torstensson-Levander, M. (2013). Malmö områdesundersökning 2012: Lokala problem, brott och trygghet.[Malmö neighborhood survey 2012: Local problems, crime and fear] Malmö: Rapport från institutionen för kriminologi, Malmö högskola.

Kornhauser, R. (1978) Social sources of delinquency: An Appraisal of Analytic Models. Chicago: Chicago university press.

Kocsis, R. N., \& Irwin, H. J. (1997). An analysis of spatial patterns in serial rape, arson, and burglary: the utility of the circle theory of environmental range for psychological profiling. Psychiatry, psychology and law, 4, 195-206. doi:

$10.1080 / 13218719709524910$ 
Lowenstein, L. F. (2003). Recent research into Arson (1992-2000): Incidence, causes and associated features, predictions, comparative studies and prevention and treatment. Psychiatry, psychology and law, 10, 192-198. doi: 10.1375/pplt.2003.10.1.192

Malmberg, B., Andersson, E. \& Östh, J. (2013). Segregation and Urban Unrest in Sweden. Urban Geography, 34, 1031-1046. doi: 10.1080/02723638.2013.799370 Malmö stad (2014). Malmö i korta drag.[Malmö in brief]. Retrieved from http://www.malmo.se/download/18.1555cde01439069ae701fec/1390808863588/Malm $\% \mathrm{C} 3 \% \mathrm{~B} 6+\mathrm{i}+$ korta + drag.pdf

Malmö stad (2016). Anmälda brott fortsätter minska. [Reported crimes continue to fall] Retrieved from http://malmo.se/Huvudnyheter/2016-04-06-Anmalda-brott-fortsatter$\underline{\text { minska.html }}$

Mazerolle, L., Wickes, R., \& McBroom, J. (2010). Community variations in violence: The role of social ties and collective efficacy in comparative context. Journal of Research in Crime and Delinquency, 47, 3-30. doi: 10.1177/0022427809348898 Meaney, R. (2004). Commuters and marauders: An examination of the spatial behaviour of serial criminals. Journal of Investigative Psychology and Offender Profiling, 1, 121-137. doi: 10.1002/jip.12

Park, R. E., \& Burgess, E. W. (1967) The City: Suggestions for the investigation of human behavior in the urban environment. University of Chicago Press, Chicago. Pooley, K. \& Ferguson, C.E. (2015). Using environmental criminology theories to compare 'youth misuse of fire' across age groups in New South Wales. Australian and New Zealand Journal of Criminology. Advance Online Publication. doi: $10.1177 / 0004865815596794$ 
Pratt, T. C., \& Cullen, F. T. (2005). Assessing macro-level predictors and theories of crime: A meta-analysis. Crime and justice, 32.373-450. Retrieved from http://www.jstor.org/stable/3488363

Sampson, R.J. (2012). Great American City. Chicago and the Enduring Neighborhood Effect. Chicago: University of Chicago press.

Sampson, R.J. \& Graif, C. (2009). Neighborhood Social Capital as Differential Social Organization: Resident and Leadership dimensions. American Behavioral Scientist, 52, 1579-1605. doi: 10.1177/0002764209331527

Sampson, R. J., \& Groves, W. B. (1989). Community structure and crime: Testing social-disorganization theory. American Journal of Sociology, 94, 774-802. doi: $10.1086 / 229068$

Sampson, R. J., \& Raudenbush, S. W. (1999). Systematic social observation of public spaces: A new look at disorder in urban Neighborhoods. American journal of sociology, 105, 603-651. doi: 10.1086/210356

Sampson, R. J., Raudenbush, S. W., \& Earls, F. (1997) Neighborhoods and Violent Crime: A Multilevel Study of Collective Efficacy. Science, 277, 918-924. doi: $10.1126 /$ science. 277.5328 .918

Sampson, R. J., \& Wikström, P.-O. H. (2008). The social order of violence in Chicago and Stockholm neighborhoods: A comparative inquiry. In S.N. Kalyvas, I. Shapiro, \& T. Masoud (Eds.), Order, conflict, and violence. (pp. 97-119) Cambridge: Cambridge University Press.

Sariaslan, A., Långström, N., D’Onofrio, B., Hallqvist, J., Franck, J., \& Lichtenstein, P. (2013). The impact of neighbourhood deprivation on adolescent violent criminality and substance misuse: a longitudinal, quasi-experimental study of the total Swedish 
population. International journal of epidemiology, 42, 1057-1066. doi:

10.1093/ije/dyt066

Shaw, C. R., \& McKay, H. D. (1969). Juvenile delinquency and urban areas. Revised edition. Chicago: Chicago University Press.

St Jean, P.K.B. (2007). Pockets of crime: Broken windows, collective efficacy and the criminal point of view. Chicago: University of Chicago press.

Statistics Sweden (2013). Fortsatt ökning av utrikes födda i Sverige. Retrieved from http://www.scb.se/sv /Hitta-statistik/Artiklar/Fortsatt-okning-av-utrikes-fodda-i-

Sverige/

Sutherland, A., Brunton-Smith, I., \& Jackson, J. (2013). Collective Efficacy, Deprivation and Violence in London. British Journal of Criminology, 53, 1050-1074. doi: $10.1093 /$ bjc/azt050

Swatt, M. L., Varano, S. P., Uchida, C. D., \& Solomon, S. E. (2013). Fear of crime, incivilities, and collective efficacy in four Miami neighborhoods. Journal of Criminal Justice, 41, 1-11. doi: 10.1016/j.jcrimjus.2012.09.004

Terjestam, Y. \& Rydén, O. (1999). Att leka med elden. En bok om barn, eld och brand.[Playing with fire. A book about children, fire and arson] Karlstad:

Räddningsverket.

Uhnoo, S. (2016). Starting a fire together: The dynamics of co-offending in juvenile arson. European Journal of Criminology, 13, 315-331. doi:

$10.1177 / 1477370815617189$

Uhnoo, S., Persson, S., Ekbrand, H. \& Lindgren, SÅ. (2015). Juvenile school firesetting in Sweden: causes and countermeasures. Journal of Scandinavian Studies in Criminology and Crime Prevention, 16. 25-40. doi: 10.1080/14043858.2014.989668 
Warner, B. D., \& Fowler, S. K. (2003). Strain and violence: Testing a general strain theory model of community violence. Journal of Criminal Justice, 31, 511-521. doi: 10.1016/j.jcrimjus.2003.08.006

Oberwittler, D., \& Wikström, P.- O. H. (2009). Why small is better: Advancing the study of the role of behavioral contexts in crime causation. In D. Weisburd, W. Bernasco, \& G.J.N. Bruinsma (Eds.) Putting crime in its place (pp. 35-59). New York: Springer.

Wikström, P.-O. H., Oberwittler, D., Treiber, K., \& Hardie, B. (2012) Breaking rules: The social and situational dynamics of young people's urban crime. Oxford: Oxford University Press.

Wilson, J. Q., \& Kelling, G. L. (1982). Broken windows. Atlantic monthly, 249, 29-38. Xu, Y., Fiedler, M. L., \& Flaming, K. H. (2005). Discovering the impact of community policing: The broken windows thesis, collective efficacy, and citizens' judgment. Journal of Research in crime and Delinquency, 42, 147-186. doi: $10.1177 / 0022427804266544$ 
Table 1. Rotated factor loadings used to weight independent variable indexes, with the factor scores achieved if ethnic heterogeneity is dropped presented in parentheses.

\begin{tabular}{|c|c|c|}
\hline Variable & $\begin{array}{l}\text { Concentrated } \\
\text { disadvantage with } \\
\text { heterogeneity }\end{array}$ & Residential instability \\
\hline Ethnic heterogeneity & $.926(-)$ & $.191(-)$ \\
\hline Proportion unemployed & $.944(.946)$ & $.168(.163)$ \\
\hline $\begin{array}{l}\text { Proportion on public } \\
\text { assistance }\end{array}$ & $.882(.903)$ & $.163(.149)$ \\
\hline Proportion foreign born & $.962(.943)$ & $.098(.101)$ \\
\hline Persons per room & $.856(.878)$ & $.192(.178)$ \\
\hline Median income (reversed) & $.871(.867)$ & $.299(.298)$ \\
\hline $\begin{array}{l}\text { Number of years as } \\
\text { resident }\end{array}$ & $.021(.024)$ & $.933(.932)$ \\
\hline $\begin{array}{l}\text { Proportion moving from } \\
\text { neighborhood }\end{array}$ & $.378(.381)$ & $.824(.823)$ \\
\hline
\end{tabular}


Table 2. Descriptive statistics for data included in the study.

\begin{tabular}{|c|c|c|c|c|}
\hline Variable & Min & Max & Mean & $\begin{array}{l}\text { Standard } \\
\text { deviation }\end{array}$ \\
\hline $\begin{array}{l}\text { Population } \\
2011\end{array}$ & 205 & 10527 & 3045 & 2110 \\
\hline $\begin{array}{l}\text { Outdoor arson } \\
\text { per } 1 \mathrm{k} \\
\text { residents } 2013\end{array}$ & 0 & 6.59 & .86 & 1.227 \\
\hline $\begin{array}{l}\text { Vehicle-related } \\
\text { arson per } 1 \mathrm{k} \\
\text { residents } 2013\end{array}$ & 0 & 3.83 & 0.36 & 0.596 \\
\hline $\begin{array}{l}\text { Collective } \\
\text { efficacy }\end{array}$ & 1.94 & 3.36 & 2.59 & 0.309 \\
\hline $\begin{array}{l}\text { Ethnic } \\
\text { heterogeneity } \\
2011\end{array}$ & 0.05 & 0.83 & 0.43 & 0.21 \\
\hline $\begin{array}{l}\text { Median } \\
\text { income } 2011\end{array}$ & 91331 & 360539 & 197995 & 52829 \\
\hline $\begin{array}{l}\text { Proportion on } \\
\text { public } \\
\text { assistance } \\
2011\end{array}$ & 0 & 48.2 & 7.0 & 8.9 \\
\hline
\end{tabular}




\begin{tabular}{|c|c|c|c|c|}
\hline $\begin{array}{l}\text { Proportion } \\
\text { foreign born } \\
2011\end{array}$ & 8.8 & 64.8 & 27.9 & 15.0 \\
\hline $\begin{array}{l}\text { Proportion } \\
\text { unemployed } \\
2011\end{array}$ & 0 & 12.8 & 3.48 & 2.75 \\
\hline $\begin{array}{l}\text { Persons per } \\
\text { room } 2011\end{array}$ & 0.49 & 1.26 & 0.71 & 0.14 \\
\hline $\begin{array}{l}\text { Mean number } \\
\text { of years as } \\
\text { resident } 2012\end{array}$ & 2.43 & 21.9 & 12.1 & 4.3 \\
\hline $\begin{array}{l}\text { Proportion } \\
\text { teenagers } \\
2011\end{array}$ & 1.1 & 15.0 & 6.9 & 3.0 \\
\hline
\end{tabular}


Table 3. Bivariate correlations for main variables.

\begin{tabular}{|c|c|c|c|c|c|c|c|c|c|}
\hline Variable & 1. & 2. & 3. & 4. & 5. & 6. & 7. & 8. & 9. \\
\hline $\begin{array}{l}\text { 1. Logarithm of out- } \\
\text { door arson per } 1000 \\
\text { residents } 2013\end{array}$ & 1 & & & & & & & & \\
\hline $\begin{array}{l}\text { 2. Logarithm of } \\
\text { Vehicle-related arson } \\
\text { per } 1000 \text { residents } 2013\end{array}$ & $.79 * *$ & 1 & & & & & & & \\
\hline $\begin{array}{l}\text { 3. Logarithm of out- } \\
\text { door arson per } 1000 \\
\text { residents } 2012-2014\end{array}$ & $.85 * *$ & $.78^{* *}$ & 1 & & & & & & \\
\hline 4. Collective efficacy & $\begin{array}{l}- \\
.26 * *\end{array}$ & $\begin{array}{l}- \\
.38 * *\end{array}$ & $\begin{array}{l}- \\
.46^{* *}\end{array}$ & 1 & & & & & \\
\hline 5. Residential instability & .08 & .09 & .19 & $\begin{array}{l}- \\
.62 * *\end{array}$ & 1 & & & & \\
\hline 6. Ethnic heterogeneity & $.44 * *$ & $.54 * *$ & $.66^{* *}$ & $\begin{array}{l}- \\
.75^{* *}\end{array}$ & $.33 * *$ & 1 & & & \\
\hline $\begin{array}{l}\text { 7. Concentrated } \\
\text { disadvantage }\end{array}$ & $.43 * *$ & $.57 * *$ & $.66^{* *}$ & $\begin{array}{l}- \\
.78 * *\end{array}$ & $.39 * *$ & $.90 * *$ & 1 & & \\
\hline $\begin{array}{l}\text { 8. Concentrated } \\
\text { disadvantage with } \\
\text { ethnic heterogeneity }\end{array}$ & $.44 * *$ & $.57 * *$ & $.67^{* *}$ & $\begin{array}{l}- \\
.79 * *\end{array}$ & $.39 * *$ & $.93 * *$ & $1 * *$ & 1 & \\
\hline
\end{tabular}




\begin{tabular}{|l|l|l|l|l|l|l|l|l|l|}
\hline 9. Proportion youth & $.21^{*}$ & $.35^{* *}$ & $.27^{* *}$ & .15 & - & .15 & .19 & .18 & 1 \\
& & & & & & & & & \\
& & & & & $.50^{* *}$ & & & & \\
\hline
\end{tabular}

Table 4. Multivariate linear regression results with the natural logarithm of outdoor arson 2013 plus one per 1000 residents.

\begin{tabular}{|c|c|c|c|c|c|c|}
\hline & M1 & & & M2 & & \\
\hline & Coefficient & Std error & $\mathrm{P}$ & Coefficient & Std error & $\mathrm{P}$ \\
\hline $\begin{array}{l}\text { Disadvantage } \\
\text { with } \\
\text { heterogeneity }\end{array}$ & .278 & .058 & .000 & .349 & .089 & .000 \\
\hline $\begin{array}{l}\text { Residential } \\
\text { instability }\end{array}$ & -.065 & .062 & .296 & -.022 & .074 & .771 \\
\hline $\begin{array}{l}\text { Collective } \\
\text { efficacy }\end{array}$ & & & & .092 & .088 & .297 \\
\hline R square & .202 & & & .212 & & \\
\hline
\end{tabular}


Table 5. Multivariate linear regression results with the natural logarithm of vehiclerelated arson in 2013 plus one per 1000 residents, including proportion of youth as independent variable.

\begin{tabular}{|c|c|c|c|c|c|c|}
\hline & Model 1 & & & Model 2 & & \\
\hline & Coefficient & Std error & $\mathrm{P}$ & Coefficient & Std error & $\mathrm{P}$ \\
\hline $\begin{array}{l}\text { Disadvantage } \\
\text { with } \\
\text { heterogeneity }\end{array}$ & .201 & .039 & .000 & .206 & .060 & .001 \\
\hline $\begin{array}{l}\text { Residential } \\
\text { instability }\end{array}$ & .011 & .047 & .821 & .013 & .051 & .803 \\
\hline $\begin{array}{l}\text { Proportion } \\
\text { youth }\end{array}$ & .087 & .035 & .014 & .086 & .036 & .018 \\
\hline $\begin{array}{l}\text { Collective } \\
\text { efficacy }\end{array}$ & & & & .006 & .054 & .912 \\
\hline $\mathrm{R}$ square & .389 & & & .389 & & \\
\hline
\end{tabular}


Figure 2. City districts in Malmö used to operationalize neighborhoods. Excluded neighborhoods have few residents and/or few community survey respondents. Remaining neighborhoods show number of vehicle-related arsons per 1000 residents registered in the neighbourhood in 2013.

${ }^{\mathrm{i}}$ In addition to the above referenced geographical-structural analyses of arson or rioting there are several other Swedish studies based on different perspectives, such as co-offending and arson, typologies for school arson and micro-sociological explanations for the spread of riots (cf. Uhnoo et al., 2015; Uhnoo, 2016; Björk, 2013)

${ }^{i i}$ When the proportion of youth is included in the factor analysis, the loadings drop for the two variables that were included in the residential instability index. Number of years as resident drops from .933 to .757 and proportion of residents who moved away from the neighbourhood drops from .824 to .789 .

iii Indexes were then re-weighted with new factor scores, but as Table 1 shows, the differences are very minor. The bivariate correlation for concentrated disadvantage and concentrated disadvantage with ethnic heterogeneity is .997 , and the bivariate correlation for residential stability based on the two different factor scores is 1 .

${ }^{\text {iv }}$ For a more detailed discussion of the arson data see Gerell (2016).

${ }^{v}$ The number of neighborhoods registering 0 on the outcome variable was 29 for 2013,17 for 2012-2014, and 49 for vehicle-related arson in 2013.

${ }^{v i}$ One neighbourhood has average levels of collective efficacy but high levels of arson (the easternmost high arson neighbourhood in Figure 2). Excluding this neighbourhood has no substantive impact on the results however. 